washing and whilst waiting to use them. This manner of taking in lead is similar to that which is found in hand-file cutters. They cut the file with a hampier and chisel, and for this purpose the file is laid on a soft block of lead. Each time the chisel strikes the file a little lead dust is knocked off the bed. In handling the file and turning it over the man constantly soils his fingers with lead dust. He then contaminates his food with lead from his hands.

During recent years it has been suggested that in the case of file-cutters, and possibly in the case of other lead-workers, this source of poisoning, by contamination of the food by lead-soiled hands, is probably of less importance than was previously thought, and that it is to the dust-laden air of the workshops and the respiration of fine lead dust that we must rather attribute the poisoning. This view seems to be based on certain animal experiments which showed that plumbism occurred more readily when lead dust was sprayed in the air than when the animals were fed on food containing 1ead. Whether it is right to conclude that similar - difference in susceptibility exists also in man seems open to question. In the case I have just related it is quite evident that the poison must have been conveyed by the hands to the food and absorbed from the alimentary canal. No dust would be likely to fly out of a vest pocket. If this was sufficient to produce severe plumbism in this case, there seems no reason why it should not be the same in the case of the file-cutters. It is obviously an important point as regards preventive measure, and I think we should be very cautious in accepting the view that persons who handle Tead dust acquire the poison by their respiratory passages rather than their digestive system.

In the history of Case 2 it seemed at first sight curious that the man should go so long without a recurrence of symptoms. The explanation seems to be that during the first few months of the year he was not shooting birds in the garden, as there was nothing for them to pick, but that with the advent of early summer his bird-shooting began again vigorously.

In conclusion, I should like to emphasise the clinical importance of Burton's line on the gums. 皱ecently some doubt has been thrown on its hæmatogenous origin, and it has been suggested that it may be due to lead dust in the mouth, deposited in the epithelium of the gum. If that is so, it follows that a person may have a blue line without having absorbed lead into the circulaision. It is claimed that this happens in lead. workers, and it is a point which is frequently raised in compensation cases. It is impossible here to go into the matter fully. Whether it is true or not in the case of lead-workers, there is no doubt whatever that in ordinary "sporadic" cases of plumbism the lead-line is due to lead salts deposited in the gum from the blood, and if it is present, even though the symptoms are "atypical" and incomplete, no pains should be spared to find the source of the poison.

Sbefinel.

'Si, Bartholomew's Medical School. - The Tollowing awards of entrance scholarships have been made at St. Bartholomew's Hospital Medical School: Senior in Science, $\& 75$ each, L. P. L. Firman-Elwards, B.A., Whitgift School and Trinity College, Cambridge, and I. G. TVlliams, B.Sc., University College, Bangor. Junior in S.jence, '£150, Campbell Shaw, Mozmouth Grammar School.

\section{TONSILS AND CHRONIC CERVICAL ADENITIS.}

By H. GARDINER, M.S. Lond,, F.R.C.S. ENG., ACTING ASSISTANT SURGEON, ROYAL FREE HOSPITAL; LATE SURGICAL REGISTRAR, GUY'S HOS'ITAL.

THE vexed question of the relation of the tonsils to the source of infection in cases of chronic cervical adenitis has been, and is being, much debated. This indecision seems largely, if not entirely, due to a lack of direct evidence of the infectivity of the tonsils in these cases. The evidence that seems to carry most weight with the general surgeon is the clinical evidence of the presence or absence of enlargement of the tonsil, and in the absence of such enlargement the tendency is to deny the probability or even possibility of the tonsil being the source of infection. Such an attitude seems scarcely reasonable in view of the fact that repeated attacks of inflammation frequently cause these organs to become sclerosed and "atrophic," and consequently less able to deal with organisms than when they are of normal size and can react by hyperplasia.

Carmichael ${ }^{1}$ in 1909 found that a high percentage of tuberculous tonsils were atrophic, and that out of 50 cases of chronic cervical adenitis 7 showed the presence of the tubercle bacillus in the tonsils. Moreover, it seems likely that these small sclerosed tonsils may even be an increased source of danger, for they combine two dangerous conditions: (1) Crypts with wider openings on the buccal surface than normal, and therefore presumably a facilitated entry for organisms; and (2) atrophy of the lymphatic tissue to deal with this invasion. Some confusion in this matter is also, no doubt, due to the frequent association of other more evident sources of infection-e.g., otitis media, pediculi capitis, carious teeth, \&c.

The following investigation was carried out with the idea of determining what, if any, evidence there was bacteriologically of the infectivity of the tonsils in cases of chronic cervical adenitis in which there was no apparent and obvious source of infection. The investigation was limited to these cases in order that the issue should be as clear as possible. For this reason not only were cases of obvious infection in the regions draining into the cervical glands excluded, but also all cases in which the glands became enlarged from below upwards and where tubercle of the lungs was also present were neglected. The method adopted was as follows.

1. In cases where the tonsils were enucleated they were transferred at once to a sterilised capsule or tin case. The capsule on the deep surface of the tonsil was then incised with all aseptic precautions, and a small portion of the deepest part of the tonsil was removed and inserted into the subcutaneous tissue of a guinea-pig. A culture was also taken from the tonsil in this region and subsequently examined.

2. In cases (only a few) where the tonsil had not been completely enucleated, and where, therefore, the tonsil (never less than two-thirds of the whole gland) was liable to infection from without, this surface was lightly cauterised and the tonsil then dealt with as above.

In this way not only was extraneous infection aroided, but the buccal surface of the tonsil was not touched. It was unfortunately impossible to examine the cervical glands themselves, as these 
were not removed at the time of operation, and the number of cases in which such an examination was possible was so small as to be useless for our purpose.

Results of Cases Investigated.

\begin{tabular}{|c|c|c|c|}
\hline $\begin{array}{l}\text { No. of } \\
\text { case. }\end{array}$ & $\begin{array}{l}\text { No. of days } \\
\text { guinea-pig } \\
\text { lived sub- } \\
\text { sequent to } \\
\text { inoculation. }\end{array}$ & Result of inoculation. & Result of culture. \\
\hline 1 & 19 & Local abscess; sterile. & Nil. \\
\hline 2 & 2 & $\begin{array}{l}\text { Pneumococcus; Fried- } \\
\text { lander's bacillus. }\end{array}$ & 一 \\
\hline 3 & 5 & $\begin{array}{c}\text { Pneumococcus; M. catar } \\
\text { rhalis. }\end{array}$ & Pneumocoecus. \\
\hline 4 & 10 & Nil. & - \\
\hline 5 & 5 & $"$ & M. catarrhalis. \\
\hline 6 & 9 & Tubercle bacillus. & Streptococcus. \\
\hline 7 & 33 & Nil. & - \\
\hline 8 & 2 & Bacillus coli communis. & Bacillus coli communis. \\
\hline 9 & 36 & Tubercle bacillus. & Streptococcus. \\
\hline 10 & 5 & Pneumococcus. & Pneumococcus. \\
\hline 11 & $?$ & Nil. & - \\
\hline 12 & 6 & , & $\begin{array}{c}\text { Staphslococcns; pneumo- } \\
\text { coccus. }\end{array}$ \\
\hline 13 & 10 & Streptococeus. & Streptococeus. \\
\hline 14 & 5 & Tubercle bacillus. & M. catarrhalis. \\
\hline 15 & 12 & Staphylocoecus. & Staphylococcus. \\
\hline 16 & 12 & Nil. & Pneumococcus. \\
\hline 17 & 21 & , & Staphylococcus. \\
\hline 18 & 21 & Streptococcus. & , \\
\hline 19 & 21 & Nil. & Nil. \\
\hline 20 & 11 & Streptococcus. & $\begin{array}{l}\text { M. catarrhalis ; strepto- } \\
\text { coccus. }\end{array}$ \\
\hline 21 & 17 & Nil. & M. catarrhalis. \\
\hline 22 & 24 & , & Nil. \\
\hline 23 & 30 & , & M. catarrhalis. \\
\hline 24 & 50 & $"$ & Bacillus coli communis. \\
\hline 25 & 44 & " & $\begin{array}{l}\text { Pneumococcus ; strepto- } \\
\text { coceus. }\end{array}$ \\
\hline 26 & 52 & $\begin{array}{l}\text { Streptococeus ; staphylo- } \\
\text { coccus. }\end{array}$ & $\begin{array}{l}\text { Streptococcus ; staphylo } \\
\text { coccus. }\end{array}$ \\
\hline 27 & 65 & Tubercle bacillus. & Nil. \\
\hline 28 & 75 & Nil. & Streptococcus. \\
\hline 29 & 16 & , & M. catarrhalis. \\
\hline 30 & 72 & : & Pneumococcus. \\
\hline
\end{tabular}

On analysing this table of 30 cases the following facts are clear. Organisms of some sort were found in 24 (i.e., 80 per cent.) of the cases. Of these organisms there were present the following:-

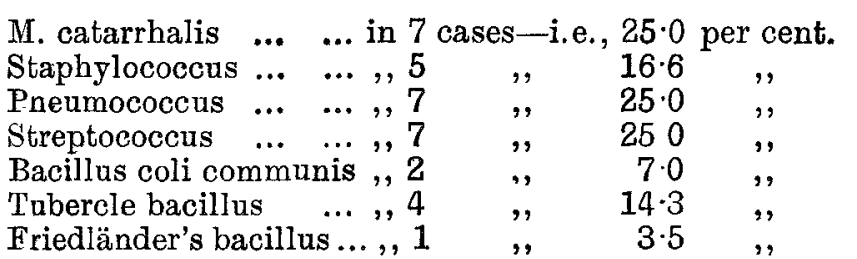

In some cases several organisms were found together and in 6 cases nothing was found; but it is possible that in 4 of these cases tubercle bacilli were present, as the guinea-pigs in these died too soon (some from purely accidental causes) for the post-mortem examination to have any absolute negative value. Comparing these results with those of other investigators, Carmichael ${ }^{1}$ found 7 cases of tuberculous tonsils out of 50 cases of tuberculous adenitis; Mitchell ${ }^{2}$ found 24 cases out of 72 ; and Kingsford ${ }^{3}$ found 7 cases out of 17 . These figures only refer to the tubercle bacillus, and they show a fairly wide variability, but there is no mention in the papers from which these figures are taken of the presence or absence of other possible-sources of infection.
With regard to the question of the tubercle bacillus, it is interesting to note that in 200 cases of enlarged tonsils (with or without glandular enlargement) Carmichael found only two cases in which the tubercle bacillus was present. Wright, ${ }^{4}$ in 1896, found no evidence of the tubercle bacillus in 60 cases of enlarged tonsils "when only the protruding portion was removed." It seems, therefore, that the tubercle bacillus is more frequently present in the tonsil in cases where the cervical glands are enlarged than in simple cases of enlarged tonsils.

With regard, however, to the results as a whole, it appears that in the great majority of cases of chronic cervical adenitis (of the nature selected) organisms are present in the deepest part of the tonsil-a part of the gland, that is to say, in very close relationship to the lymphatic spaces draining into the neck, and it seems not unlikely that their growth there has a marked influence on the enlarged cervical lymphatic glands. The nature of this influence may be one of two kinds: 1 . It may be the direct means of allowing organisms to gain access to the lymphatics, and so to the glands. 2. The organisms may so cripple the tonsil as to allow other organisms to enter the lymphaticsorganisms which perhaps, as has been held by some, pass through the tonsil without growing there. However this may be, this pathological evidence of the infectivity of the tonsil is supported by the clinical evidence that in a large number of these cases the glandular enlargement disappears after the enucleation of the tonsils; the persistence of the glands in some cases after the removal. of the tonsils being explained probably by the low resisting power of the patient to the infection that has already taken place.

Two other points of importance become evident from this investigation: (1) The question as to the value of the enlargement of the tonsil as evidence. of its infectivity; and (2) the bearing of the abore: results on the question of enucleation versus partial removal of the tonsil. With regard to the first of these points, I think it cannot be too. strongly urged that the size of the tonsil is of no. value as evidence of its infection with organisms. In fact, from the evidence of the cases I examined. I would go even further and say that the small atrophic tonsil, with its wide-mouthed crypts and deficient lymphoid tissue, is of much more dangerto the patient than is the enlarged hrpertrophic. tonsil. This is a point of the first importance, for it istoo frequently the case that surgeons refuse to. accept a tonsil as a possible source of infection unless it is obviously enlarged. It is true that a tonsil reacting to infection by vaso-dilatation and hyperplasia is necessarily enlarged, but the tonsil that has undergone repeated attacks of inflammation and has become the seat of almost complete fibrosis with loss of nearly all its glandular substances-it is easy to see how such a tonsil may offer no resistance to bacterial invasion and so. show no signs of hyperplasia. In the series of cases tabulated above 18 were of this type and in: only three of these were no organisms found.

With regard to the second point-i.e., of enucleation versus partial remoral-it is clear that all the evidence of this series of cases is in farour of, and in fact demands, the complete operation. For in 80 per cent. of the cases examined organisms were found in the deepest parts of the gland-i.e., immediately adjacent to the capsule. It therefore is not surprising that the partial removal of the tonsil with the guillotine is in many cases followed by no. 
diminution in the size of the glands; in fact, this procedure may do more harm than good, as it not only leaves part of the infected organ behind, but also leaves a raw surface to heal by scarring and the subsequent formation of those very pocket-like crypts which seem so dangerous.

\section{Conclusions.}

1. In the majority of cases ( 80 per cent.) of chronic cervical adenitis where no obvious source of infection is present the tonsils are infected.

2. The size of the tonsil makes no difference to their infectivity, except that the small fibrotic variety is likely to be more dangerous than the large.

3. The number of cases in which tubercle bacilli are present is relatively small, but is larger than in simple cases of enlarged tonsils.

4. The frequent presence of other organisms than the tubercle bacillus in these cases suggests that a large proportion of the so-called chronic tuberculous glands are in reality chronic septic glands.

5. The organisms are present in the deepest parts of the gland, and are therefore only removed by operations involving complete enucleation.

My sincere thanks are due to the surgeons and assistant surgeons at Guy's Hospital; to Mr. J. F. O'Malley, of the Evelina Hospital for Children; and to Mr. G. E. Waugh, of Great Ormond-street Hospital, for their valuable assistance in providing most of the above cases.

Biblingraphy.-1. Carmichael: Proceedings of the Royal Society of Medicine, November, 1909. 2. Mitchell : Brit. Med. Jour., Julv 1ith, 1914. 3. Kingsford: THE LaxcET. Jan. 9th, 1904, p. 89. 4. Wright: New York Medical Record, June 26th, 1909.

Wimpole-s' reet, W.

\section{SHRAPNEL LOCATED AT BACK OF ORBIT: SUCCESSFUL EXTRACTION.}

By SIR WILLIAM J. COLLINS, K.C.V.O., M.S., M.D., B.Sc. Lond., F.R.C.S. ENG.,

OPHTHALMIC SURGEON TO KING GEORGE HOSPITAL AND SENIOR SURGEON TO THE ROYAL EYE TOSPITAL.

Rifleman - aged 21, was struck by two shells near Ypres on July 4th. One struck him in the face, "blinding" him, and the other inflicted several wounds on the left arm. At the first dressing station shrapnel was removed from the arm, and the eyes, which could not be opened, were bandaged. He was conveyed to Poperinghe, where it was found that the left eye was uninjured and the vision of it good. The lids of the right eye were separated with difficulty owing to swelling of the conjunctiva, and the vision was reduced to bare perception of light. Five days later he was transferred to Boulogne and thence to King George Hospital, where he was admitted on July 23 rd.

On admission the patient showed evidence of shock and suffered from pain in the right side of the head and from insomnia. There was some "peppering" of the nose and left cheek with small fragments of shrapnel, and there were several suppurating wounds in the left upper arm. The right eye showed great chemosis, the conjunctiva overlapping the cornea and rendering separation of the lids difficult and painful. There was slight proptosis. The anterior chamber contained a little greyish-green pus, and there was no vision. The vision of the left eye was normal, pupil active, no photophobia. No external wound in the neighbour. hood of the right orbit could be detected. A radiogram taken by Dr. W. Ironside Bruce showed a large fragment of shapnel, apparently situated deeply in the right orbit adjacent to the base of the skull. No cerebral symptoms were detected though the patient was "nervy," complained of severe headache, and could not sleep. His temperature rose at night to about $101^{\circ} \mathrm{F}$., but this might be due to the condition of his left arm.

On July 28th, under chloroform and ether ad. ministered by Dr. P. F. Wilson, I examined the right eye and excised it; in cutting the optic nerve my scissors scraped against metal. Some small splinters of bone were removed on irrigating the socket. I then passed the index finger deeply into the orbit,

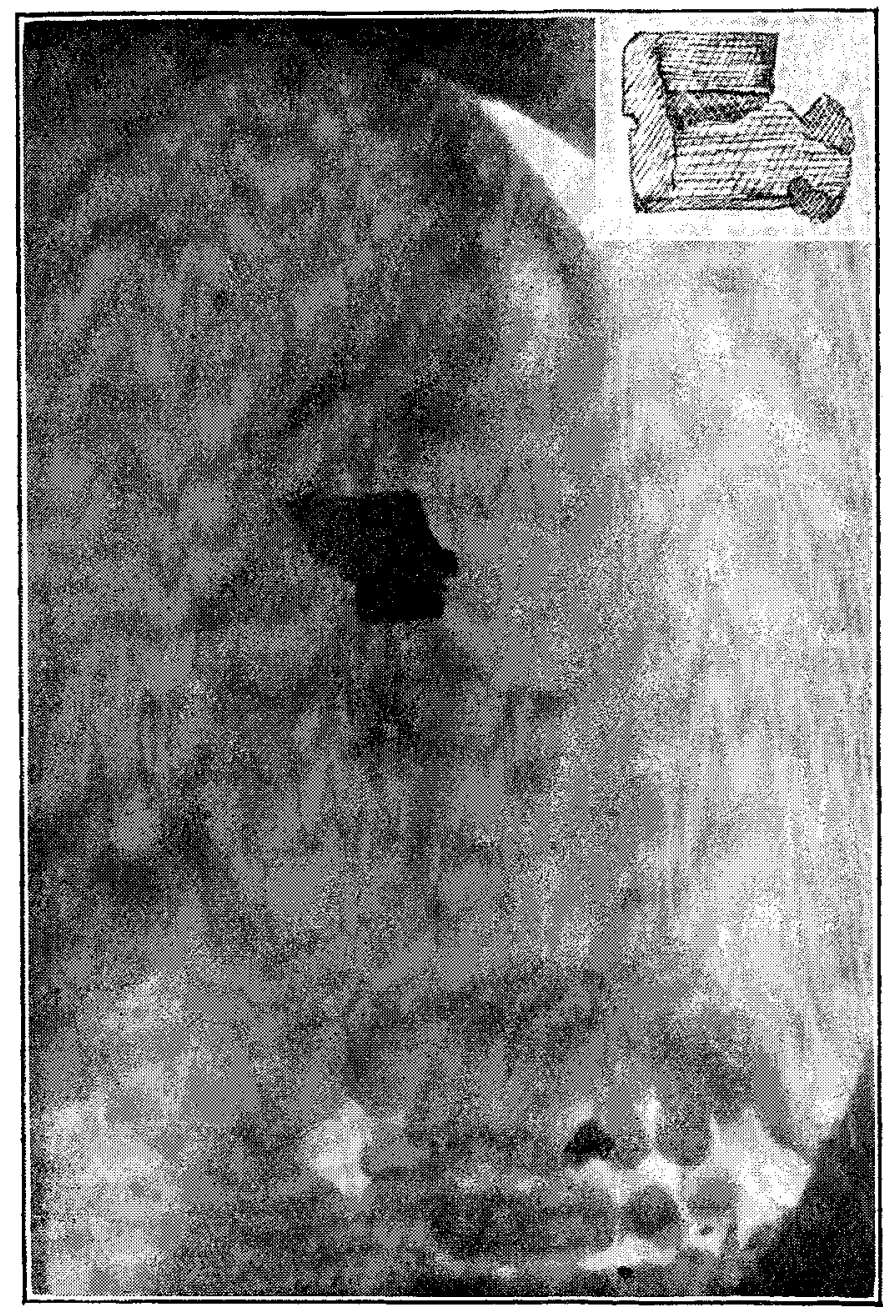

Skiagram showing the piece of shrapnel in silu. The inset shows projectile, exact size.

and at its apex detected a large piece of metal jammed into or against the inner and posterior walls of the orbit. I passed a pair of stout sequestrum forceps along $m y$ finger and seized the fragment; rotating it gently, I freed it from the bone and cautiously extracted it. No other foreign body nor loose fragments of bone were to be found, and after thorough irrigation with boracic acid lotion some iodoform was puffed in, a fair-sized drainage-tube from the back of the orbit inserted, and the orbit lightly dressed. Mr. J. Eduardo Rivera (house surgeon) assisted me. Before the patient recovered from the anæsthetic Mr. F. S. Piggott scraped the sinuses in the left arm and inserted tubes.

The excised eye was in a condition of pan. ophthalmitis, the vitreous chamber contained pus; the recti and their sheaths were adherent to the globe and a furrow appeared to have been cut in the equatorial region of the eye on its inner aspect. Presumably the foreign body had entered through the palpebral fissure and passed between the globe 